\title{
Determination of lanthanides in rock samples by inductively coupled plasma mass spectrometry using thorium as oxide and hydroxide correction standard
}

\author{
Narendra M. Raut ${ }^{\mathrm{a}}$, Li-Shing Huang ${ }^{\mathrm{b}}$, Suresh K. Aggarwal ${ }^{\mathrm{a}}$, King-Chuen Lin ${ }^{\mathrm{b}} *$ \\ ${ }^{a}$ Fuel Chemistry Division, Bhabha Atomic Research Center, Trombay, Mumbai, 400 085, India \\ ${ }^{\mathrm{b}}$ Department of Chemistry, National Taiwan University, and Institute of Atomic and Molecular Sciences, Academia Sinica,
} Taipei 106, Taiwan, ROC

Received 12 September 2002; accepted 7 February 2003

\begin{abstract}
Determination of lanthanides by Inductively Coupled Plasma Mass Spectrometry (ICP-MS) using modified mathematical correction method has been studied. Normally, the ICP-MS analysis of middle and heavier lanthanides becomes difficult by severe spectroscopic overlap of $\mathrm{M}^{+}, \mathrm{MO}^{+}$or $\mathrm{MOH}^{+}$ions from lighter lanthanides and $\mathrm{Ba}$. A correction method based on a single element oxide yield measurement, is a simple approach to correct for the above spectroscopic overlaps. But the uncertainty in the oxide and hydroxide yields measurement of lanthanides and barium over a long period of time can lead to inaccurate results even under fixed plasma conditions. To correct this, thorium was adopted as an oxide and hydroxide correction standard. Using a ratio of lanthanide oxide yield to thorium oxide yield, the lanthanide correction factors (LCF) were established and incorporated in the mathematical correction scheme. The same factors were also established for hydroxide correction. The proposed modified correction scheme was applied to the determination of lanthanides by ICP-MS from the USGS Standard Rock samples AGV-1 and G2. The results are in good agreement with the reported values. The method also proved to be useful in isotopic ratio measurement of lanthanides having severe isobaric overlaps.
\end{abstract}

(c) 2003 Elsevier Science B.V. All rights reserved.

Keywords: Lanthanides; Rock samples; Inductively coupled plasma mass spectrometry

\section{Introduction}

The lanthanides represent a group of elements from $\mathrm{La}$ to $\mathrm{Lu}$ that shows very similar physical and chemical properties. The analytical determinations of these elements are useful in view of their applications in geochemistry, nuclear fuel

\footnotetext{
*Corresponding author. Fax: + 886-2-2362-1483.

E-mail address: kclin@ccms.ntu.edu.tw (K.-C. Lin).
}

chemistry, environmental science, industries, etc. [1-4]. By taking advantage of multi-elemental detection capabilities along with high selectivity and sensitivity, Inductively Coupled Plasma Mass Spectrometry (ICP-MS) has been regarded as a better analytical tool for lanthanides than other conventional techniques [5]. The feasibility of the analysis of lanthanides in rock samples by ICPMS was first demonstrated by Date and Gray using acid-digested sample solutions [6]. Later, several 
researchers published a variety of schemes for determination of lanthanides in various geological samples [7-11]. The main advantage of ICP-MS is that it allows the analysis of lanthanides especially in geological samples without any chemical separation or pre-concentration [12]. Due to the high mass of lanthanides, they do not get interfered with by doubly charged species of other elements. However, accurate measurement is still not easy due to spectroscopic interference from isobaric atomic ions and polyatomic ions like oxides and hydroxides, etc. $[13,14]$. The serious difficulty will be encountered in the determination of heavier lanthanides by ICP-MS when the concentration ratio of lighter lanthanide to heavier lanthanide is high. In addition, $\mathrm{Ba}$ is usually found to be the most abundant element in many samples, and, therefore, its oxides and hydroxides can interfere with some middle lanthanides, especially $\mathrm{Eu}$ [15].

Several methods have been adopted to reduce the metal oxide formation in the ICP torch. The use of desolvation techniques including ultrasonic nebuliser [16], membrane dryer [17], and cryogenic desolvation [18] may effectively reduce the water load in the plasma to restrict the oxide formation. Other efforts such as changes in plasma gas composition [19-21], changes in sampler and skimmer orifice size [22], optimization of the distance between them [23], and changes in sampling depth [17] could also limit the oxide formation to some level. Mathematical correction provides an alternative approach to solve the oxide and hydroxide overlap problem, with advantages of the speed and the ease of application without any additional experimental modifications [2426]. However, one should be cautious in using the correction scheme due to the poor stability of oxides and hydroxides formed in the plasma [27]. The oxide or hydroxide yield, obtained by analyzing an interfering lanthanide standard solution, is normally used in the mathematical correction scheme to estimate its contribution in determination of analyte lanthanide. It was reported that the oxide yield of lanthanides could change as high as $30 \%$ within $3 \mathrm{~h}$ [28]. Hence, for multiple sample determination requiring a long period of time, the oxide and hydroxide yield may not be the same as that determined in the standards.
To overcome above difficulties, an internal standard is used to correct the analyte oxide/hydroxide signal changes caused by any fluctuations in plasma parameters or due to matrix effect. To serve as an appropriate internal standard, its atomic isotopes, oxide/hydroxide, and polyatomic ions should not spectroscopically interfere with any atomic isotope or polyatomic ion of the analyte. Its oxide and hydroxide yielding behavior should also be the same as that of analyte. Thorium is a mono-isotopic element with $\mathrm{m} / z=232$ (singly charged ion) or 116 (doubly charged ion). Th singly or doubly charged ion and its polyatomic species [ThO, $(m / z=248)$ or ThOH, $(m / z=249)$ ] do not come in the $m / z$ range of lanthanides $(\mathrm{m} /$ $z=138-176)$. Due to very high mass, it does not get isobarically interfered with by any element isotope or polyatomic ion in the natural samples. Like lanthanides, it is a strong oxide/hydroxideforming element in the plasma.

In this work, we adopt thorium as an oxide and hydroxide correction standard. The oxide and hydroxide yielding behavior of Th is thoroughly studied along with all lanthanides and $\mathrm{Ba}$ to further inspect its suitability. Then, ratios of lanthanide oxide yield to thorium oxide yield, defined as lanthanide correction factors (LCF), were evaluated and incorporated in a mathematical correction scheme to correct for the spectroscopic interference and eliminate the time-dependent drift of the oxide and hydroxide yields. The combination of ICP-MS and correction scheme is finally applied to USGS certified rock samples (AGV-1 and G-2) analysis for accurate determination of lanthanides and isotope ratios.

\section{Experimental}

\subsection{Apparatus}

A SCIEX ELAN 6000 ICP-MS (Perkin-Elmer, USA), as described elsewhere [29], was used for all data acquisition. It was run in sequential mode, peak hopping to masses of interest. A cross flow nebuliser served as a sprayer for sample introduction. In an effort to avoid conductive coupling between the load coil and the plasma, both ends of the load coil were biased with high voltage of 
equal amplitude but opposite phase. No modification was made to the load coil configuration. The sampling depth between the sampler tip and top coil was fixed at $9 \mathrm{~mm}$ for all data acquisition. The coolant gas flow rate and the auxiliary gas flow rate were fixed at 15.0 and $1.01 / \mathrm{min}$, respectively, throughout the experiment. The radio frequency (R.F.) power $(1150 \mathrm{~W})$ and the aerosol gas flow rate $(1.0 \mathrm{l} / \mathrm{min})$ were optimized using $10 \mathrm{ppb} \mathrm{Ce}$ solution for maximum $\mathrm{Ce}^{+}$signal and the minimum possible $\mathrm{CeO}^{+} / \mathrm{Ce}^{+}$ratio.

\subsection{Reagents}

De-ionized water (Millipore, USA) was used for the preparation of solutions. Indium (1000 $\mathrm{ppm})$ and Thorium as thorium nitrate were procured from Merck and Indian Rare Earth Ltd., respectively. All the lanthanides $10 \mathrm{ppm}$ each and $\mathrm{Ba}(1000 \mathrm{ppm})$ standard solution were purchased from High-Purity Standards, USA and diluted to desired concentrations by $1 \% \mathrm{HNO}_{3}$. Certified rock samples AGV-1 and G-2 used for the determination of lanthanides and $\mathrm{Ba}$ were obtained from United State Geological Survey. Trace Pure grade $\mathrm{HNO}_{3}$ and Supra grade HF from Merck were used for digestion and dissolution of rock samples. Finally, all the solutions and samples were prepared in $1 \%$ $\mathrm{HNO}_{3}$ for ICP-MS analysis.

\subsection{Digestion of rock samples}

It is very important to use an appropriate digestion method in ICP-MS analysis of lanthanides. Especially, for determination of lanthanides in silicate rock, sample preparation is not straightforward. Incomplete digestion and loss of volatile species are two main problems in it. Ultrasonic extraction is one of the promising techniques for speeding up and simplifying sample treatment [30]. The localized high-energy environment formed by the application of ultrasound was employed for extraction of lanthanides from solid silicate matrices in conc. $\mathrm{HF}$ and conc. $\mathrm{HNO}_{3}$ medium. Twenty-five milligrams of AGV-1 was dissolved in PTFE beaker using a mixture of 0.5 $\mathrm{ml}$ conc. HF and $5 \mathrm{ml}$ conc. $\mathrm{HNO}_{3}$, by heating on a hot plate followed by ultra-sonication, for 1.5-
$2.0 \mathrm{~h}$. To extract the ultra-trace heavier lanthanides in $\mathrm{G}-2$, the above digestion medium was modified by using 1:1 $\mathrm{HCl}-\mathrm{HNO}_{3}$ in place of $\mathrm{HNO}_{3}$. The ultra-sonication extraction time was also increased from 2 to $5 \mathrm{~h}$. The dissolved solutions showed almost no residue after the ultra-sonic extraction. These solutions were further subjected to evaporation to dryness to remove excess fluorides and chlorides from $\mathrm{HF}$ and $\mathrm{HCl}$, respectively. They were further treated 2-3 times with conc. $\mathrm{HNO}_{3}$ to evaporate till dryness followed by their dilution to the desired volume with $1 \% \mathrm{HNO}_{3}$ for ICP-MS analysis.

\section{Modification in mathematical correction method}

The correction scheme depends on the measurement of single element standard for the $\%$ oxide or hydroxide yield of each lanthanide and $\mathrm{Ba}$. The equation for single oxide or hydroxide species correction described elsewhere [31] is as follows

$E=\frac{e \cdot x \cdot b \cdot R}{y \cdot P}$

where $e$ is an oxide or hydroxide yield of interfering element in its standard solution, $x$ is the observed intensity of interfering element isotope with natural abundance $P$ in its standard solution, $y$ is the observed intensity of analyte isotope in its standard solution, $b$ is the natural abundance of isobarically interfering isotope over analyte in sample, and $R$ is the observed ratio of concentrations of interfering element $\left(L_{B}\right)$ to analyte element $\left(L_{A}\right)$ in a given unknown sample. As the signal of analyte element is spectroscopically interfered with by interfering element in the sample, the calculated error (E) using this $R$ value would be incorrect. To improve it, the following equation obtained by iterative procedure should be used (see Appendix A)

$E^{\prime}=\frac{100 \cdot E}{100-E}$

if the error is expressed in \%. The above Eqs. (1) 
and (2) are limited to the precision of the determined $e$ value, which cannot remain constant over a long period, as mentioned in Section 1. In this work, we use Lanthanide Correction Factors (LCF) to substitute the $e$ term. The LCF, defined as the ratio of oxide yield of interfering element to that of Th, is a measured factor, which turns out to be suitable for the oxide drift correction. According to the definition, LCF for oxides $\left(F_{\mathrm{LnO}}\right)$ is expressed as

$F_{\mathrm{LnO}}=\frac{I_{\mathrm{LnO}} / I_{\mathrm{Ln}}}{I_{\mathrm{ThO}} / I_{\mathrm{Th}}}$

or

$e_{1}=e_{\mathrm{ThO}} \cdot F_{\mathrm{LnO}}$

where $e_{1}=\frac{I_{\mathrm{LnO}}}{I_{\mathrm{Ln}}}$ and $e_{\mathrm{ThO}}=\frac{I_{\mathrm{ThO}}}{I_{\mathrm{Th}}}$ are the yields of lanthanide oxide and thorium oxide, respectively. Substituting Eq. (4) in Eq. (1) gives

$E_{1}=\frac{e_{\mathrm{ThO}} \cdot F_{\mathrm{LnO}} x_{1} \cdot b_{1} \cdot R_{1}}{y_{1} \cdot P_{1}}$

where the subscript ' 1 ' indicates the isobaric correction from the oxides of lighter lanthanides. Similarly for hydroxide species, the modified correction equation is

$E_{2}=\frac{e_{\mathrm{ThOH}} \cdot F_{\mathrm{LnOH}} x_{2} \cdot b_{2} \cdot R_{2}}{y_{2} \cdot P_{2}}$

where $e_{\mathrm{ThOH}}$ is hydroxide yield of Th in a sample, and $F_{\mathrm{LnOH}}$ is the LCF of interfering element for hydroxide correction. For correction of atomic isobaric interference amongst lanthanides, the equation is expressed as

$E_{3}=\frac{100 \cdot x_{3} \cdot b_{3} \cdot R_{3}}{y_{3} \cdot P_{3}}$

Given a measured value of $R_{i}(i=1,2$ and 3$)$ in an unknown sample, Eqs. (5)-(7) may be treated individually via iterative procedure to give a corrected $\%$ error $\left(E_{i}{ }^{\prime}, i=1,2\right.$ and 3$)$ similar to that in Eq. (2). $E_{1}{ }^{\prime}, E_{2}{ }^{\prime}$ and $E_{3}{ }^{\prime}$ denote the error correction for oxide, hydroxide and atomic isobaric interfering lanthanides, respectively. Hence, the total error contribution from all types of isobaric species is given by

$E_{\text {total }}=\sum_{i=1}^{l} E_{1}^{\prime} i+\sum_{j=1}^{m} E_{2}^{\prime} j+\sum_{k=1}^{n} E_{3}^{\prime} k$

\section{Results and discussion}

It is always advisable that the isotope of an element in a sample used for ICP-MS analysis should have preferably no isobaric interference from atomic isotopes or polyatomic ions. If all the isotopes of an element show isobaric overlaps, then the isotope chosen for analysis should be the one with least overlaps. Lanthanides are the elements that form strongest oxides in the plasma [32]. The oxide yield is higher for lighter lanthanides than that of heavier lanthanides. As the $m / z$ of these high yielding oxides of lighter lanthanides is same as that of heavier lanthanides, they cause serious spectroscopic overlaps over the mass number of heavier lanthanides. Ba shows less oxide or hydroxide yield than lanthanides, but it is normally found at higher concentration in natural samples compared to the lanthanides. This leads to significant interference from the barium oxide and hydroxide overlap with some middle and heavier lanthanides. Keeping these points in mind, asterisk isotopes of lanthanides in Table 1 were accordingly chosen for the ICP-MS analysis in this work. In and Th were added in the samples as internal standard and oxide/hydroxide correction standard, respectively.

The use of Th as an oxide and hydroxide correction standard has been reported earlier [33] where both oxide and hydroxide species were normalized by ThO. Our study shows that the ratio of $\mathrm{ThO}^{+} / \mathrm{ThOH}^{+}$does not remain constant when the optimized parameters like aerosol gas flow rate and RF power were changed (Fig. 1a,b). It sug- 
Table 1

Spectroscopic interferences on selected lanthanides isotopes in their ICP-MS analysis

\begin{tabular}{|c|c|c|c|}
\hline Lanthanide & Mass & $\%$ Abundance & Interferences \\
\hline $\mathrm{La}$ & $139^{*}$ & 99.91 & - \\
\hline $\mathrm{Ce}$ & $140^{*}$ & 88.48 & - \\
\hline $\operatorname{Pr}$ & $141^{*}$ & 100.0 & - \\
\hline \multirow[t]{2}{*}{$\mathrm{Nd}$} & $143^{*}$ & 12.18 & - \\
\hline & 150 & 5.64 & ${ }^{134} \mathrm{Ba}^{16} \mathrm{O},{ }^{150} \mathrm{Sm}$ \\
\hline \multirow[t]{3}{*}{$\mathrm{Sm}$} & $147^{*}$ & 15.00 & ${ }^{130} \mathrm{Ba}^{16} \mathrm{OH}$ \\
\hline & 152 & 26.7 & ${ }^{136} \mathrm{Ba}^{16} \mathrm{O},{ }^{136} \mathrm{Ce}^{16} \mathrm{O},{ }^{135} \mathrm{Ba}^{16} \mathrm{OH},{ }^{152} \mathrm{Gd}$ \\
\hline & 154 & 22.7 & ${ }^{138} \mathrm{Ba}^{16} \mathrm{O},{ }^{138} \mathrm{La}^{16} \mathrm{O},{ }^{138} \mathrm{Ce}^{16} \mathrm{O},{ }^{137} \mathrm{Ba}^{16} \mathrm{OH},{ }^{154} \mathrm{Gd}$ \\
\hline \multirow[t]{2}{*}{$\mathrm{Eu}$} & $151^{*}$ & 47.8 & ${ }^{135} \mathrm{Ba}^{16} \mathrm{O},{ }^{134} \mathrm{Ba}^{16} \mathrm{OH}$ \\
\hline & 153 & 52.2 & ${ }^{137} \mathrm{Ba}^{16} \mathrm{O},{ }^{136} \mathrm{Ba}^{16} \mathrm{OH}$ \\
\hline \multirow{2}{*}{$\mathrm{Gd}$} & 156 & 20.47 & ${ }^{140} \mathrm{Ce}^{16} \mathrm{O},{ }^{139} \mathrm{La}^{16} \mathrm{OH},{ }^{156} \mathrm{Dy}$ \\
\hline & $157^{*}$ & 15.65 & ${ }^{141} \operatorname{Pr}^{16} \mathrm{O},{ }^{140} \mathrm{Ce}^{16} \mathrm{OH}$ \\
\hline $\mathrm{Tb}$ & $159^{*}$ & 100.0 & ${ }^{143} \mathrm{Nd}^{16} \mathrm{O},{ }^{142} \mathrm{Ce}^{16} \mathrm{OH},{ }^{142} \mathrm{Nd}^{16} \mathrm{OH}$ \\
\hline \multirow[t]{3}{*}{ Dy } & 161 & 18.9 & ${ }^{145} \mathrm{Nd}^{16} \mathrm{O},{ }^{144} \mathrm{Nd}^{16} \mathrm{OH},{ }^{144} \mathrm{Sm}^{16} \mathrm{OH}$ \\
\hline & 162 & 25.5 & ${ }^{146} \mathrm{Nd}^{16} \mathrm{O},{ }^{145} \mathrm{Nd}^{16} \mathrm{OH}$ \\
\hline & $163^{*}$ & 24.9 & ${ }^{147} \mathrm{Sm}^{16} \mathrm{O},{ }^{146} \mathrm{Nd}^{16} \mathrm{OH}$ \\
\hline Ho & $165^{*}$ & 100.0 & ${ }^{149} \mathrm{Sm}^{16} \mathrm{O},{ }^{148} \mathrm{Nd}^{16} \mathrm{OH},{ }^{148} \mathrm{Sm}^{16} \mathrm{OH}$ \\
\hline \multirow[t]{3}{*}{$\mathrm{Er}$} & 166 & 33.6 & ${ }^{150} \mathrm{Nd}^{16} \mathrm{O},{ }^{150} \mathrm{Sm}^{16} \mathrm{O},{ }^{149} \mathrm{Sm}^{16} \mathrm{OH}$ \\
\hline & $167^{*}$ & 22.95 & ${ }^{151} \mathrm{Eu}^{16} \mathrm{O},{ }^{150} \mathrm{Nd}^{16} \mathrm{OH},{ }^{150} \mathrm{Sm}^{16} \mathrm{OH}$ \\
\hline & 168 & 26.80 & ${ }^{152} \mathrm{Sm}^{16} \mathrm{O},{ }^{152} \mathrm{Gd}^{16} \mathrm{O},{ }^{151} \mathrm{Eu}^{16} \mathrm{OH}$ \\
\hline $\mathrm{Tm}$ & $169^{*}$ & 100.0 & ${ }^{153} \mathrm{Eu}^{16} \mathrm{O},{ }^{152} \mathrm{Sm}^{16} \mathrm{OH},{ }^{152} \mathrm{Gd}^{16} \mathrm{OH}$ \\
\hline \multirow[t]{2}{*}{$\mathrm{Yb}$} & $171^{*}$ & 14.3 & ${ }^{155} \mathrm{Gd}^{16} \mathrm{O},{ }^{154} \mathrm{Sm}^{16} \mathrm{OH},{ }^{154} \mathrm{Gd}^{16} \mathrm{OH}$ \\
\hline & 174 & 31.8 & ${ }^{158} \mathrm{Gd}^{16} \mathrm{O},{ }^{158} \mathrm{Dy}{ }^{16} \mathrm{O},{ }^{157} \mathrm{Gd}^{16} \mathrm{OH},{ }^{174} \mathrm{Hf}$ \\
\hline $\mathrm{Lu}$ & $175^{*}$ & 97.41 & ${ }^{159} \mathrm{~Tb}^{16} \mathrm{O},{ }^{158} \mathrm{Gd}^{16} \mathrm{OH}$ \\
\hline
\end{tabular}

* Isotopes having no or minor interferences selected for qualitative analysis. The remaining isotopes having severe interferences were used for isotope ratio measurement.

gests that the normalization of hydroxide species by $\mathrm{ThO}$ is not an appropriate approach.

\subsection{Effect of aerosol gas flow rate on oxide and hydroxide formation}

The factors of aerosol gas flow rate and radio frequency (RF) power have been reported to be the most critical operating parameters to affect the analyte signals in ICP-MS [34,35]. These two parameters are also important for oxide and hydroxide formation in the plasma. High aerosol gas flow rate decreases the aerosol residence time and temperature of plasma. As a result, it tends to increase the oxide and hydroxide formation in plasma. As the aerosol gas flow rate was adjusted in the range $0.85-1.11 / \mathrm{min}$, the oxide yields of lanthanides were found to vary from 60 to $340 \%$ of their oxide yields at optimized rate $1.0 \mathrm{l} / \mathrm{min}$ (Fig. 2a). Under the same condition, $\mathrm{BaO}$ changed from 36 to $227 \%$. ThO, as monitored simultaneously, was used to normalize the changes in oxide formation of lanthanides and Ba. Fig. 2b,c shows the normalization of a lanthanide oxide $(\mathrm{CeO})$ and $\mathrm{BaO}$ by $\mathrm{ThO}$. The normalized oxide yields, i.e. the LCFs were found to be almost constant with respect to the change of aerosol gas flow rate studied. For other interfering lanthanides, they were found to be consistent within 10-32\% (Table 2).

The hydroxide yielding behavior of lanthanides, $\mathrm{Ba}$ and $\mathrm{Th}$ were studied similarly. As shown in Fig. 3a, the hydroxide yields of $\mathrm{Th}, \mathrm{Ce}$ and $\mathrm{Ba}$ behave along almost the same trend in the range $0.85-1.2 \mathrm{l} / \mathrm{min}$ of aerosol gas flow rate. Thus, the $\mathrm{LCF}$ of $\mathrm{Ce}$ and $\mathrm{Ba}$ remain almost constant, irrespective of the change of the aerosol gas flow rate (Fig. 3b,c). Such normalized hydroxide yields of lanthanides and $\mathrm{Ba}$ are listed in Table 2. The LCFs for hydroxides were found to be consistently with- 

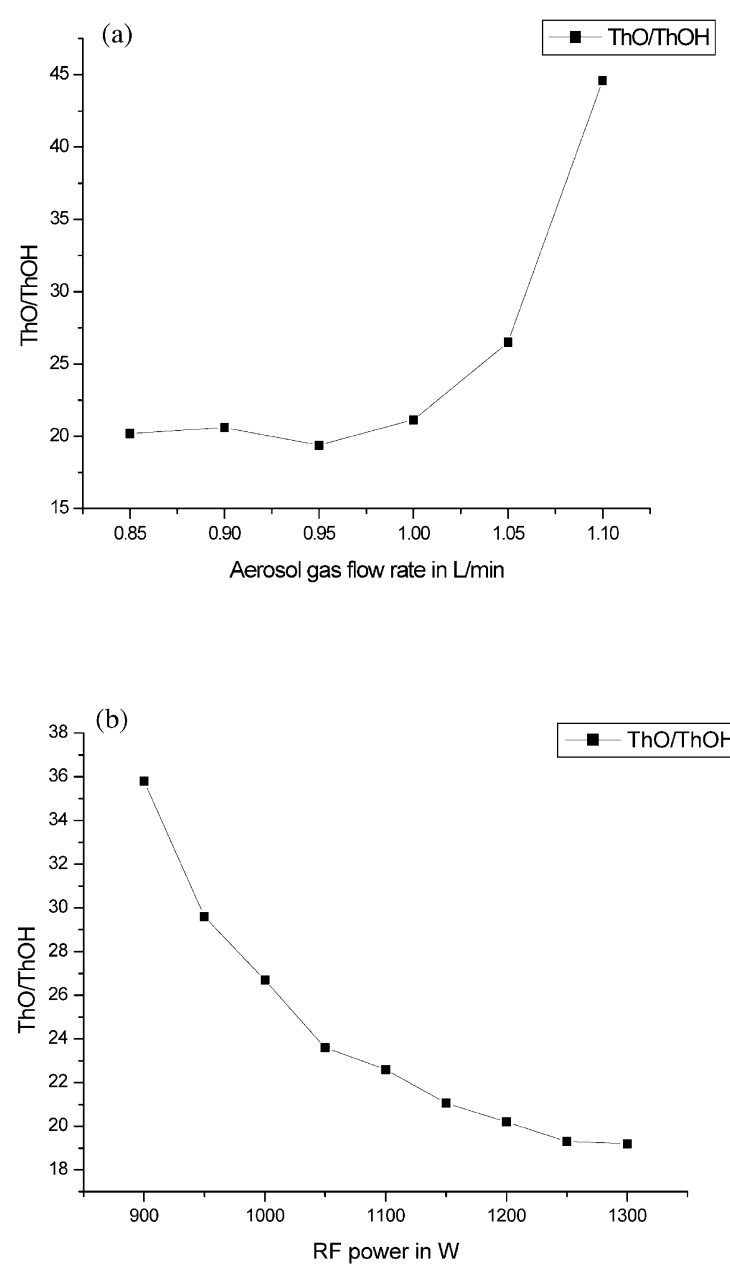

Fig. 1. Effect of plasma parameters over the oxide and hydroxide formation of Th: (a) aerosol gas flow rate; and (b) RF power.

in $20 \%$ for most of the lanthanides, except for Sm and $10 \%$ for $\mathrm{Ba}$.

\subsection{Effect of RF power on oxide and hydroxide formation}

The increase in the RF power increases temperature of the plasma, leading to partial decomposition of $\mathrm{MO}$ and the increase of the $\mathrm{M}$ yield. As a result, the $\mathrm{MO}^{+} / \mathrm{M}^{+}$ratio decreases with the increase of the RF power. Fig. 4a shows the effect of the $\mathrm{RF}$ power on $\mathrm{CeO}^{+} / \mathrm{Ce}^{+}, \mathrm{BaO}^{+} / \mathrm{Ba}^{+}$and $\mathrm{ThO}^{+} / \mathrm{Th}^{+}$. As the $\mathrm{RF}$ power was varied in the range 900-1300 $\mathrm{W}$, the oxide formation reduced from 215 to $80 \%$ with respect to oxide yield at optimized RF power $(1150 \mathrm{~W})$ for lanthanides, 200 to $70 \%$ for Ba, and 210 to $85 \%$ for Th. Since their oxide yields behaved similarly in the range
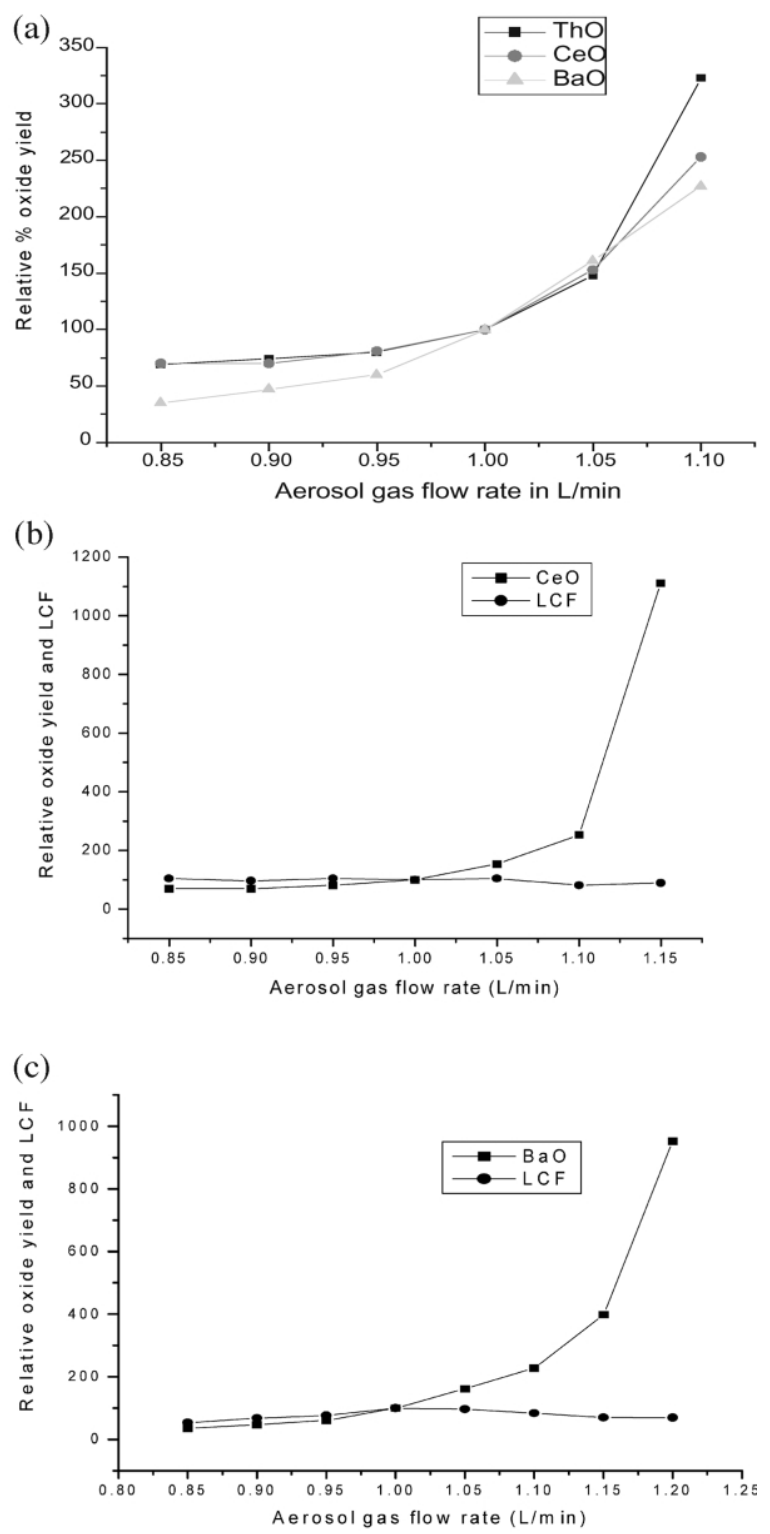

Fig. 2. Effect of aerosol gas flow rate over (a) oxide yields of lanthanide $(\mathrm{Ce}), \mathrm{Ba}$ and $\mathrm{Th}$ with respect to optimized aerosol gas flow rate (1 1/min), (b) $\mathrm{CeO}$ yield and $\mathrm{LCF}$ for $\mathrm{CeO}$ interference, and (c) $\mathrm{BaO}$ yield and $\mathrm{LCF}$ for $\mathrm{BaO}$ interference. 
Table 2

Effect of aerosol gas flow rate on the LCF of lanthanides in the range $0.85-1.10 \mathrm{l} / \mathrm{min}(n=6)$

\begin{tabular}{lll}
\hline Element & $\begin{array}{l}\text { Mean LCF } \\
\text { for oxide } \\
\text { (\% R.S.D.) }\end{array}$ & $\begin{array}{l}\text { Mean LCF* } \\
\text { for hydroxide } \\
\text { (\% R.S.D.) }\end{array}$ \\
\hline $\mathrm{La}$ & $0.456(10)$ & $0.536(5)$ \\
$\mathrm{Ce}$ & $0.550(10)$ & $0.415(12)$ \\
$\mathrm{Pr}$ & $0.508(25)$ & $0.185(23)$ \\
$\mathrm{Nd}$ & $0.497(31)$ & $0.232(14)$ \\
$\mathrm{Sm}$ & $0.079(23)$ & $0.054(33)$ \\
$\mathrm{Eu}$ & $0.008(20)$ & $0.031(19)$ \\
$\mathrm{Gd}$ & $0.247(17)$ & $0.214(17)$ \\
$\mathrm{Tb}$ & $0.229(22)$ & $0.067(25)$ \\
$\mathrm{Ba}$ & $0.013(32)$ & $0.155(10)$ \\
\hline
\end{tabular}

${ }^{*}$ For hydroxide yield and LCF for hydroxide, the aerosol gas flow rate range was $0.85-1.21 / \mathrm{min}(n=8)$.

of RF power studied, the LCF of $\mathrm{Ce}$ and $\mathrm{Ba}$ became almost constant (Fig. 4b,c). The LCF obtained for other interfering lanthanides were reproducible within $15 \%$ in the same range and the variation in the LCF of $\mathrm{Ba}$ was found to be within $11 \%$ (Table 3 ).

Similarly, the study of hydroxide shows that lanthanides and Ba produce 130-90\% hydroxide with respect to their hydroxide yield at optimized $\mathrm{RF}$ power $(1150 \mathrm{~W})$ in the above-mentioned range for oxides. Table 3 shows the improvement in the uncertainty of hydroxide yields of lanthanides and $\mathrm{Ba}$ after their normalization by $\mathrm{ThOH}$.

\subsection{Establishment of lanthanide correction factor $(L C F)$}

The effects of RF power and aerosol gas flow rate show that the oxide and hydroxide formation of lanthanides, $\mathrm{Ba}$ and $\mathrm{Th}$ behave similarly under different plasma conditions. Hence, Th is suitable to be adopted as an oxide and hydroxide correction standard to improve the uncertainties in the measurement of lanthanides. To examine the extent of variation in oxide and hydroxide formation under the fixed optimized plasma conditions, the same individual solutions of lanthanides ( $\mathrm{La}$ to $\mathrm{Tb}$ ) and $\mathrm{Ba}$ were monitored on different days. Data in Table 4 show that the uncertainty in the oxide and hydroxide measurement for 5 different days was within $9-24 \%$ for $\mathrm{La}$ to $\mathrm{Tb}$, and 20 and $12 \%$ for
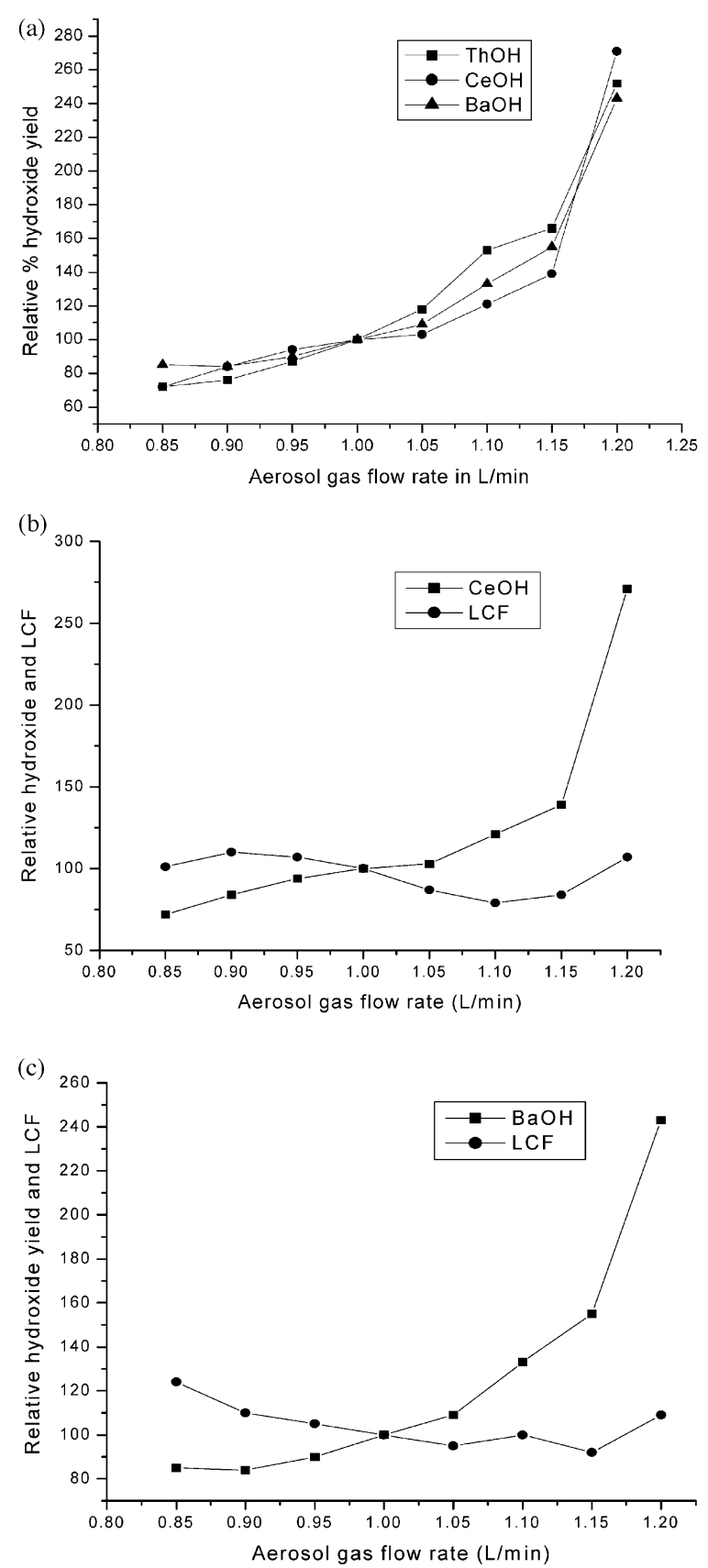

Fig. 3. Effect of aerosol gas flow rate over (a) hydroxide yields of lanthanide $(\mathrm{Ce}), \mathrm{Ba}$ and $\mathrm{Th}$ with respect to optimized aerosol gas flow rate $(1 \mathrm{l} / \mathrm{min})$, (b) $\mathrm{CeOH}$ yield and $\mathrm{LCF}$ for $\mathrm{CeOH}$ interference, and (c) $\mathrm{BaOH}$ yield and $\mathrm{LCF}$ for $\mathrm{BaOH}$ interference. 

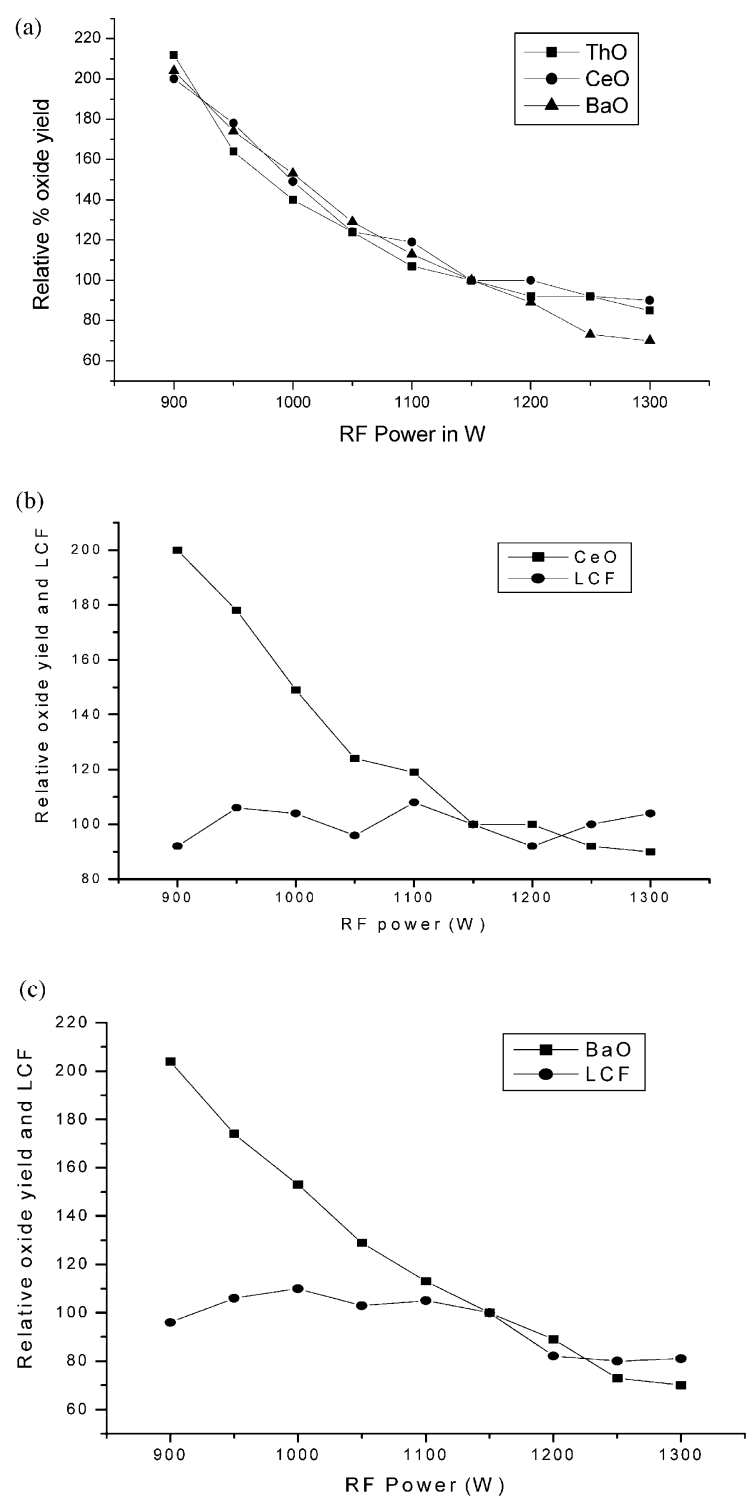

Fig. 4. Effect of RF power over (a) oxide yields of lanthanide (Ce), Ba and Th with respect to optimized RF power (1150 $\mathrm{W}$ ), (b) $\mathrm{CeO}$ yield and $\mathrm{LCF}$ for $\mathrm{CeO}$ interference, and (c) $\mathrm{BaO}$ yield and $\mathrm{LCF}$ for $\mathrm{BaO}$ interference.

barium oxide and barium hydroxide, respectively. Under the same conditions, the thorium oxide shows $12 \%$ and thorium hydroxide shows $17 \%$ fluctuations. The use of $\mathrm{Th}$ as an oxide and hydroxide correction standard was shown to reduce the uncertainties in measurement of these oxide yields within $6 \%$ for lanthanides and $\mathrm{Ba}$. The lanthanide correction factors evaluated in Tables 2-4 for oxide and hydroxide correction were found to be almost the same. These factors are used in the mathematical correction with Eqs. (5)-(8).

\subsection{Validation of modified correction scheme}

The validation of the modified correction method as shown in Eqs. (5)-(8), is examined by determination of the lanthanides from the USGS certified rock samples AGV-1 and G-2. AGV-1 and G-2 rock samples were analyzed approximately $2 \mathrm{~h}$ after analyzing lanthanides standard solutions for their oxide and hydroxide yields. The results are tabulated in Tables 5 and 6 for AGV-1 and G-2, respectively. To check the usefulness of the modified scheme, the error corrections for the isobaric interfering species by Eqs. (1) and (2) and Eqs. (5)-(8), respectively, are compared. By using the correction schemes in Eqs. (1) and (2), which consider only the oxide or hydroxide yields of interfering elements, the error in the determination of $\mathrm{AGV}-1$ for $\mathrm{Eu}$ was reduced from 20 to $9 \%$, for Gd from 39 to $14 \%$, for $\mathrm{Tb}$ from 17 to $6 \%$, for Dy from 7 to $6 \%$ and for $\mathrm{Yb}$ from 3 to $2 \%$. Similarly, in the case of G-2, the error for Eu was reduced from 27 to $9 \%$, for Gd 88 to $32 \%$, for $\mathrm{Tb} 44$ to $17 \%$, for Dy 10 to $9 \%$, for Ho 2.5 to $0 \%$ and for Er 5 to $4 \%$. The oxide and hydroxide yield observed in standards and in the samples analyzed $2 \mathrm{~h}$ later gives raise to 40 and $56 \%$ of

Table 3

Effect of RF power on the LCF of lanthanides in the range 900-1300 W $(n=9)$

\begin{tabular}{lll}
\hline Element & $\begin{array}{l}\text { Mean LCF } \\
\text { for oxide } \\
\text { (\% R.S.D.) }\end{array}$ & $\begin{array}{l}\text { Mean LCF } \\
\text { for hydroxide } \\
\text { (\% R.S.D.) }\end{array}$ \\
\hline $\mathrm{La}$ & $0.463(4)$ & $0.540(5)$ \\
$\mathrm{Ce}$ & $0.556(5)$ & $0.448(4)$ \\
$\mathrm{Pr}$ & $0.482(12)$ & $0.221(4)$ \\
$\mathrm{Nd}$ & $0.462(15)$ & $0.232(7)$ \\
$\mathrm{Sm}$ & $0.087(11)$ & $0.062(8)$ \\
$\mathrm{Eu}$ & $0.011(12)$ & $0.026(5)$ \\
$\mathrm{Gd}$ & $0.257(10)$ & $0.220(5)$ \\
$\mathrm{Tb}$ & $0.230(13)$ & $0.081(5)$ \\
$\mathrm{Ba}$ & $0.0163(10)$ & $0.158(8)$ \\
\hline
\end{tabular}


Table 4

Change in the oxide and hydroxide yields, and LCF of lanthanides under fixed optimized plasma conditions observed on five different days $(n=5)$

\begin{tabular}{lllll}
\hline Element & $\begin{array}{l}\text { Mean \% } \\
\text { oxide yield } \\
\text { (\% R.S.D.) }\end{array}$ & $\begin{array}{l}\text { Mean LCF } \\
\text { for oxide } \\
\text { (\% R.S.D.) }\end{array}$ & $\begin{array}{l}\text { Mean \% } \\
\text { hydroxide yield } \\
\text { (\% R.S.D.) }\end{array}$ & $\begin{array}{l}\text { Mean LCF } \\
\text { for hydroxide } \\
(\% \text { R.S.D.) }\end{array}$ \\
\hline $\mathrm{Th}$ & $4.78(12)$ & - & $0.25(17)$ & - \\
$\mathrm{La}$ & $2.16(12)$ & $0.462(5)$ & $0.12(15)$ & $0.556(3)$ \\
$\mathrm{Ce}$ & $2.63(9)$ & $0.565(4)$ & $0.09(15)$ & $0.430(4)$ \\
$\mathrm{Pr}$ & $2.47(10)$ & $0.531(6)$ & $0.05(12)$ & $0.217(5)$ \\
$\mathrm{Nd}$ & $2.30(12)$ & $0.493(4)$ & $0.06(11)$ & $0.227(7)$ \\
$\mathrm{Sm}$ & $0.41(11)$ & $0.087(4)$ & $0.02(14)$ & $0.066(6)$ \\
$\mathrm{Eu}$ & $0.05(24)$ & $0.012(7)$ & $0.01(21)$ & $0.026(5)$ \\
$\mathrm{Gd}$ & $1.17(14)$ & $0.245(4)$ & $0.06(18)$ & $0.222(5)$ \\
$\mathrm{Tb}$ & $1.08(9)$ & $0.226(4)$ & $0.02(16)$ & $0.081(3)$ \\
$\mathrm{Ba}$ & $0.09(20)$ & $0.017(4)$ & $0.04(12)$ & $0.152(5)$ \\
\hline
\end{tabular}

drift, respectively. Due to the time-dependent drift, even after mathematical correction using the oxide yields observed in the standards, higher errors in analysis of $\mathrm{Eu}, \mathrm{Gd}$ and $\mathrm{Tb}$ for both samples are found. To eliminate the effect of the time-dependent drift in the oxide and hydroxide formation, a normalization of oxide and hydroxide yields of lanthanides and $\mathrm{Ba}$ by $\mathrm{ThO}$ and $\mathrm{ThOH}$ is treated in the modified correction scheme. Given the LCF in Table 4 for oxide and hydroxide correction, the errors evaluated by Eqs. (5)-(8) for analysis of the lanthanides from both samples are also listed in Tables 5 and 6. The modified scheme reduced the time-dependent drift error in determination of $\mathrm{Eu}$ from 20 to $2 \%$, for $\mathrm{Gd} 39$ to $1 \%$ and for $\mathrm{Tb}$ 17 to $0 \%$ in AGV-1. Similarly, in G-2 the error is reduced for Eu from 27 to $1 \%$, for Gd from 88 to $2 \%$, for $\mathrm{Tb}$ from 44 to $2 \%$, for Dy from 10 to $8 \%$

Table 5

Lanthanides determination in AGV-1 in units of ppmw, using Th as oxide and hydroxide correction standard

\begin{tabular}{lcccc}
\hline Ln & $\begin{array}{l}\text { USGS } \\
\text { recommended } \\
\text { concentration }\end{array}$ & $\begin{array}{l}\text { Uncorrected } \\
\text { concentration }\end{array}$ & $\begin{array}{l}\text { Corrected } \\
\text { concentration } \\
\text { without LCF }\end{array}$ & $\begin{array}{l}\text { Corrected } \\
\text { concentration } \\
\text { using LCF }^{\text {b }}\end{array}$ \\
\hline $\mathrm{La}$ & $38 \pm 3$ & $40.03(5)$ & $40.03(5)$ & $40.03(5)$ \\
$\mathrm{Ce}$ & $67 \pm 5$ & $72.92(9)$ & $72.92(9)$ & $72.92(9)$ \\
$\mathrm{Pr}$ & $7.6 \pm 1.1$ & $8.86(17)$ & $8.86(17)$ & $8.86(17)$ \\
$\mathrm{Nd}$ & $33 \pm 3$ & $34.26(4)$ & $34.26(4)$ & $6.26(4)$ \\
$\mathrm{Sm}$ & $5.9 \pm 0.4$ & $6.24(6)$ & $6.24(6)$ & $6.24(6)$ \\
$\mathrm{Eu}$ & $1.6 \pm 0.1$ & $1.92(20)$ & $1.75(9)$ & $1.63(2)$ \\
$\mathrm{Gd}$ & $5.0 \pm 0.5$ & $6.94(39)$ & $5.70(14)$ & $0.74(6)$ \\
$\mathrm{Tb}$ & $0.7 \pm 0.1$ & $0.82(17)$ & $3.82(6)$ & $0.70(0)$ \\
$\mathrm{Dy}$ & $3.6 \pm 0.3$ & $3.84(7)$ & $0.70(5)$ & $3.80(6)$ \\
$\mathrm{Ho}$ & $0.67 \pm 0.1$ & $0.70(5)$ & $1.96(15)$ & $0.69(3)$ \\
$\mathrm{Er}$ & $1.7 \pm 0.2$ & $1.96(15)$ & $0.27(21)$ & $1.95(15)$ \\
$\mathrm{Tm}$ & $0.34 \pm 0.13^{\mathrm{c}}$ & $0.27(21)$ & $1.69(2)$ & $0.27(21)$ \\
$\mathrm{Yb}$ & $1.72 \pm 0.19$ & $1.77(3)$ & $0.26(4)$ & $1.67(3)$ \\
$\mathrm{Lu}$ & $0.27 \pm 0.03$ & $0.27(0)$ & $0.26(4)$ \\
\hline
\end{tabular}

a The parenthesized values indicate \% error, determined by (uncorrected concentration-USGS recommended concentration) $\times 100 /$ USGS recommended concentration.

b The parenthesized values indicate $\%$ error, determined by (corrected concentration - USGS recommended concentration) $\times 100 /$ USGS recommended concentration.

${ }^{\mathrm{c}}$ Provisional value. 
Table 6

Lanthanides determination in G-2 in units of ppmw, using Th as oxide and hydroxide correction standard

\begin{tabular}{|c|c|c|c|c|}
\hline Ln & $\begin{array}{l}\text { USGS } \\
\text { recommended } \\
\text { concentration }\end{array}$ & $\begin{array}{l}\text { Uncorrected } \\
\text { concentration }^{\mathrm{a}}\end{array}$ & $\begin{array}{l}\text { Corrected } \\
\text { concentration } \\
\text { without } \mathrm{LCF}^{\mathrm{b}}\end{array}$ & $\begin{array}{l}\text { Corrected } \\
\text { concentration } \\
\text { using } \mathrm{LCF}^{\mathrm{b}}\end{array}$ \\
\hline $\mathrm{La}$ & $89 \pm 8$ & $94.49(6)$ & 94.49 (6) & 94.49 (6) \\
\hline $\mathrm{Ce}$ & $160 \pm 10$ & $171.62(7)$ & $171.62(7)$ & $171.62(7)$ \\
\hline $\operatorname{Pr}$ & $18 \pm 2$ & $17.38(3)$ & $17.38(3)$ & $17.38(3)$ \\
\hline $\mathrm{Nd}$ & $55 \pm 6$ & $57.22(4)$ & $57.22(4)$ & $57.22(4)$ \\
\hline $\mathrm{Sm}$ & $7.2 \pm 0.7$ & $7.79(8)$ & $7.79(8)$ & $7.79(8)$ \\
\hline $\mathrm{Eu}$ & $1.4 \pm 0.1$ & $1.78(27)$ & $1.53(9)$ & $1.39(1)$ \\
\hline $\mathrm{Gd}$ & $4.3 \pm 0.8$ & $8.09(88)$ & $5.66(32)$ & $4.37(2)$ \\
\hline $\mathrm{Tb}$ & $0.48 \pm 0.08$ & $0.69(44)$ & $0.56(17)$ & $0.49(2)$ \\
\hline Dy & $2.4 \pm 0.3$ & $2.64(10)$ & $2.62(9)$ & 2.59 (9) \\
\hline Ho & $0.4 \pm 0.06$ & $0.41(3)$ & $0.40(0)$ & $0.40(0)$ \\
\hline $\mathrm{Er}$ & $0.92 \pm 0.18$ & $0.97(5)$ & $0.96(4)$ & $0.95(3)$ \\
\hline $\mathrm{Tm}$ & $0.18 \pm 0.08^{\mathrm{c}}$ & $0.12(33)$ & $0.12(33)$ & $0.12(33)$ \\
\hline $\mathrm{Yb}$ & $0.8 \pm 0.17$ & $0.74(8)$ & $0.64(20)$ & $0.62(23)$ \\
\hline $\mathrm{Lu}$ & $0.11 \pm 0.02$ & 0.09 (18) & $0.08(27)$ & $0.08(27)$ \\
\hline
\end{tabular}

${ }^{a}$ The parenthesized values indicate $\%$ error, determined by (uncorrected concentration-USGS recommended concentration) $\times 100 /$ USGS recommended concentration.

b The parenthesized values indicate $\%$ error, determined by (corrected concentration - USGS recommended concentration) $\times 100 /$ USGS recommended concentration.

${ }^{\mathrm{c}}$ Provisional value.

and for Er 5 to $3 \%$. The values obtained in our work for heavier lanthanides such as $\mathrm{Yb}$ and $\mathrm{Lu}$ are lower in G-2 analysis than those in USGS recommendation. The same trend was also observed by Aggarwal et al. [36].

The modified correction scheme is useful especially in a large number of sample analysis where the analysis time is prolonged. The normal analysis procedure includes the analysis of standards before and after the analysis of sample to obtain the correct oxide yields of lanthanides. For a large number of samples analysis, the above procedure becomes elaborate. The use of established LCF eliminates the need of standard analysis for oxide and hydroxide yield measurement.

\subsection{Isotope ratio correction}

As discussed earlier, the minor atomic or polyatomic spectroscopic overlaps can be effectively corrected using the modified scheme given in Eqs. (5)-(8). From Table $1,{ }^{139} \mathrm{La},{ }^{140} \mathrm{Ce},{ }^{141} \mathrm{Pr},{ }^{143} \mathrm{Nd}$, ${ }^{147} \mathrm{Sm},{ }^{151} \mathrm{Eu},{ }^{157} \mathrm{Gd},{ }^{163} \mathrm{Dy},{ }^{167} \mathrm{Er},{ }^{171} \mathrm{Yb}$ and ${ }^{175} \mathrm{Lu}$ show no or least polyatomic isobaric interferences, while ${ }^{150} \mathrm{Nd},{ }^{152} \mathrm{Sm},{ }^{154} \mathrm{Sm},{ }^{153} \mathrm{Eu},{ }^{156} \mathrm{Gd},{ }^{161} \mathrm{Dy}$,
${ }^{162} \mathrm{Dy},{ }^{166} \mathrm{Er}$ and ${ }^{174} \mathrm{Yb}$ isotopes show severe atomic and polyatomic isobaric interferences. To check the suitability of the correction scheme for major spectroscopic interferences, the lanthanide isotopes with higher spectroscopic overlaps were subjected to correction by a modified scheme using LCF (Table 7). The resultant isotopic ratios of major and minor spectroscopically overlapped isotopes, observed in the rock samples without correction, deviated markedly from the corresponding natural isotopic ratios. After the mathematical correction, the determined isotopic ratios were improved significantly for almost all lanthanides, especially for ${ }^{143} \mathrm{Nd} /{ }^{150} \mathrm{Nd},{ }^{154} \mathrm{Sm} /{ }^{147} \mathrm{Sm}$, and ${ }^{152} \mathrm{Sm} /{ }^{147} \mathrm{Sm}$, where ${ }^{150} \mathrm{Nd},{ }^{152} \mathrm{Sm}$ and ${ }^{154} \mathrm{Sm}$ are severely interfered by $\mathrm{BaO}$ or $\mathrm{BaOH}$.

In analysis of AGV-1, the error was reduced from 89 to $11 \%$ for ${ }^{156} \mathrm{Gd} /{ }^{157} \mathrm{Gd}$ ratio, from 64 to $5 \%$ for ${ }^{154} \mathrm{Sm} /{ }^{147} \mathrm{Sm}$, from 23 to $5 \%$ for ${ }^{143} \mathrm{Nd} /$ ${ }^{150} \mathrm{Nd}$, from 11 to $2 \%$ for ${ }^{162} \mathrm{Dy} /{ }^{163} \mathrm{Dy}$, etc. Similarly, in G-2, the error was reduced from 194 to $15 \%$ for ${ }^{156} \mathrm{Gd} /{ }^{157} \mathrm{Gd}$ ratio, from 74 to $10 \%$ for ${ }^{154} \mathrm{Sm} /{ }^{147} \mathrm{Sm}$, from 19 to $4 \%$ for ${ }^{143} \mathrm{Nd} /{ }^{150} \mathrm{Nd}$, from 36 to $2 \%$ for ${ }^{162} \mathrm{Dy} /{ }^{163} \mathrm{Dy}$, from 18 to $2 \%$ for ${ }^{163} \mathrm{Dy} /{ }^{161} \mathrm{Dy}$, and from 20 to $2 \%$ for ${ }^{166} \mathrm{Er} /$ 
Table 7

Isotope ratio correction

\begin{tabular}{|c|c|c|c|c|c|}
\hline Isotopic ratio & $\begin{array}{l}\text { Natural } \\
\text { ratio }\end{array}$ & $\begin{array}{l}\text { Isotope ratio } \\
\text { in AGV-1 } \\
\text { before } \\
\text { correction }^{\mathrm{a}}\end{array}$ & $\begin{array}{l}\text { Isotope ratio } \\
\text { in AGV-1 } \\
\text { after } \\
\text { correction }^{\mathrm{a}}\end{array}$ & $\begin{array}{l}\text { Isotope ratio } \\
\text { in G-2 } \\
\text { before } \\
\text { correction }^{\mathrm{a}}\end{array}$ & $\begin{array}{l}\text { Isotope ratio } \\
\text { in G-2 } \\
\text { After } \\
\text { Correction }^{\mathrm{a}}\end{array}$ \\
\hline${ }^{143} \mathrm{Nd} /{ }^{150} \mathrm{Nd}$ & 2.16 & $1.66(23)$ & $2.05(5)$ & $1.76(19)$ & $2.07(4)$ \\
\hline${ }^{154} \mathrm{Sm} /{ }^{147} \mathrm{Sm}$ & 1.51 & $2.48(64)$ & $1.44(5)$ & $2.63(74)$ & $1.37(10)$ \\
\hline${ }^{152} \mathrm{Sm} /{ }^{147} \mathrm{Sm}$ & 1.78 & $1.92(8)$ & $1.78(0)$ & 1.99 (12) & $1.81(2)$ \\
\hline${ }^{153} \mathrm{Eu} /{ }^{151} \mathrm{Eu}$ & 1.09 & $1.20(10)$ & $1.13(3)$ & $1.22(12)$ & $1.09(0)$ \\
\hline${ }^{156} \mathrm{Gd} /{ }^{157} \mathrm{Gd}$ & 1.31 & $2.48(89)$ & $1.17(10)$ & 3.84 (194) & $1.01(15)$ \\
\hline${ }^{162} \mathrm{Dy} /{ }^{163} \mathrm{Dy}$ & 1.02 & $1.13(11)$ & $1.00(2)$ & $1.39(36)$ & $1.01(2)$ \\
\hline${ }^{163} \mathrm{Dy} /{ }^{161} \mathrm{Dy}$ & 1.32 & $1.25(5)$ & $1.37(4)$ & $1.08(18)$ & $1.35(2)$ \\
\hline${ }^{166} \mathrm{Er} /{ }^{167} \mathrm{Er}$ & 1.46 & $1.54(8)$ & 1.44 (1) & $1.75(20)$ & $1.43(2)$ \\
\hline${ }^{174} \mathrm{Yb} /{ }^{171} \mathrm{Yb}$ & 2.22 & $2.21(1)$ & 2.20 & $2.16(3)$ & $2.19(2)$ \\
\hline
\end{tabular}

a The parenthesized values indicate $\%$ error in isotope ratio determination with reference to natural isotopic ratio.

${ }^{167} \mathrm{Er}$. The rest of the ratios agreed with the natural isotopic ratios within $4 \%$ uncertainty. The over corrections appeared in some of the isotope ratios like ${ }^{156} \mathrm{Gd} /{ }^{157} \mathrm{Gd},{ }^{154} \mathrm{Sm} /{ }^{147} \mathrm{Sm}$ etc., where one of the isotopes (e.g. ${ }^{156} \mathrm{Gd}$ and ${ }^{154} \mathrm{Sm}$ ) in a selected pair is severely interfered. The more the interference correction is treated, the higher the uncertainty in corrected isotope signal will be. This may result in over or under estimation of corrected signals and hence, the corrected isotopic ratios. However, the improvement in the isotope ratios after correction by the developed method in the present work gives extra confidence on the correction scheme using LCF.

It has been known that quadrupole based ICPMS cannot compete with Thermal Ionization Mass Spectrometry (TIMS) in isotope ratio determination in terms of accuracy and precision. But the major advantage of ICP-MS using mathematical correction is the high sample throughput that results from its ability to analyze bulk solution without separation of individual analyte and matrix. After sample dissolution, the ICP-MS analysis of one sample takes less than $10 \mathrm{~min}$ with less consumption of sample. In contrast, tedious and time consuming chemical separation, source filament preparation and loading are prerequisites for TIMS analysis. Nowadays, high resolution ICPMS with multi-collector (ICP-MC-MS) can give precision values comparable with those obtained by TIMS. Walder et al. measured isotope ratios of
$\mathrm{Nd}$, Sm and other transition elements using ICPMC-MS having seven Faraday detectors with accuracy and precision obtainable by TIMS [37,38]. Hence, the developed technique with ICP-MC-MS promises rapid and accurate analysis for isotope ratios determination of lanthanides. The high precision measurements obtained by these instruments can reduce the uncertainty in the corrected analyte signal and therefore can yield more accurate results than those obtained by quadrupole based mass spectrometer in the present work. The above methodology is useful in areas of nuclear chemistry, geochemistry, and especially geochronology where measurement of isotopic ratio with high accuracy and precision is of great concern.

The proposed methodology in this paper can be applied for accurate determination of lanthanides using different types of ICP mass spectrometers available commercially. Since the yield of oxide production varies depending upon the instrumental design and the type of plasma used, it is therefore advisable to determine the LCFs under the exact experimental conditions to achieve high accuracy.

\section{Conclusions}

A modified correction scheme has been developed for rapid and accurate determination of lanthanides contained in a large number of samples which otherwise require a long time for analysis. Th has been characterized to have the same oxide 
and hydroxide-yielding behavior as those of lanthanides. By using Th as an oxide and hydroxide correction standard to eliminate the time-dependent drift or any fluctuation in plasma parameters, we may avoid the change of the oxide and hydroxide yield during the analysis. The use of established LCF can also eliminate the need of standard analysis for oxide and hydroxide yield measurement. The accurate determination of the isotope ratios in rock samples AGV-1 and G-2 suggests that the correction scheme should be conducive to correction of severe polyatomic isobaric interferences. Since the isotope ratio measurement of lanthanides is of great importance in nuclear chemistry and geochronology, the ICP-MS technique incorporating the correction scheme may serve as an alternative promising tool.

\section{Acknowledgments}

This work is financially supported by National Science Council, Republic of China under contract no. NSC 90-2113-M-002-036. N.M.R. is thankful to Institute of Atomic and Molecular Sciences, Academia Sinica, for providing Ph.D. fellowship and research facilities during the collaboration.

\section{Appendix A:}

In the following is a derivation of the iterative procedure to improve the correction scheme expressed in Eq. (1). $R$ denoted in Eq. (1) is defined as the observed ratio of concentration of interfering element $\left(L_{B}\right)$ to analyte element $\left(L_{A}\right)$ in a given unknown sample. That is,

$R=\frac{L_{B}}{L_{A}}$

Substitution of $R$ into Eq. (1) yields

$E=\frac{K}{L_{A}}$

where

$K=\frac{e \cdot x \cdot b \cdot L_{B}}{y \cdot P}$
During the sample analysis, if the analyte signal intensity has interference, the concentration of analyte $\left(L_{A}\right)$ and hence, the estimated error $(E)$ would be incorrect. The error estimation may be improved to $E_{1}$ by considering an approximated correct concentration of analyte $L_{A_{1}}$, which is expressed by

$L_{A_{1}}=\frac{L_{A}}{1+E}$

Then

$E_{1}=\frac{K}{L_{A_{1}}}=\frac{K(1+E)}{L_{A}}=E+E^{2}$

To improve it further to $E_{2}$, the procedures similar to Eqs. (A4) and (A5) should be repeated. A better approximation of analyte concentration $L_{A_{2}}$ is given by

$L_{A_{2}}=\frac{L_{A}}{1+E_{1}}$

Then

$E_{2}=\frac{K}{L_{A_{2}}}=\frac{K\left(1+E_{1}\right)}{L_{A}}=E+E^{2}+E^{3}$

On repeating the above steps for ' $n$ ' number of times, $E_{n}$ may be obtained by

$E_{n}=\sum_{i=1}^{n+1} E^{i}$

or

$E_{n}=\frac{E\left(1-E^{n+1}\right)}{(1-E)}$

To obtain the correct error $\left(E^{\prime}\right)$, the above steps should be repeated infinitely

$E^{\prime}=E_{\infty}=\frac{E\left(1-E^{\infty}\right)}{(1-E)}$ 
As $E$ is a fraction $(1>E \geq 0), E^{\infty} \rightarrow 0$. Thus

$E^{\prime}=\frac{E}{1-E}$

If the error is expressed in $\%$, then

$E^{\prime}=\frac{100 \cdot E}{100-E}$

as given in Eq. (2).

\section{References}

[1] T. Prohaska, S. Hann, C. Latkoczy, G. Stingeder, Determination of rare earth elements, $U$ and $T h$ in environmental samples by inductively coupled plasma double focussing sectorfield mass spectrometry, J. Anal. At. Spectrom. 14 (1999) 1-8.

[2] K. Inagaki, H. Haraguchi, Determination of rare earth elements in human blood serum by inductively coupled plasma mass spectrometry after chelating resin preconcentration, Analyst 125 (2000) 191-196.

[3] F. Gunter, Principles of Isotope Geology, 2nd ed, John Wiley, New York, 1986.

[4] F.H. Spedding, A.H. Daan, The Rare Earths, John Wiley, New York, 1961.

[5] M. Ochsenkuhn-Petropoulou, K. Ochsenkuhn, J. Luck, Comparison of inductively coupled plasma mass spectrometry with inductively coupled plasma atomic emission spectrometry and instrumental neutron activation analysis for the determination of rare earth elements in Greek bauxites, Spectrochim. Acta Part B 46 (1991) 51-65.

[6] A.R. Date, A.L. Gray, Determination of trace elements in geological samples by inductively coupled plasma source mass spectrometry, Spectrochim. Acta Part B 40 (1985) 115-122.

[7] A.R. Date, D. Hutchison, Determination of rare earth elements in geological samples by inductively coupled plasma mass spectrometry, J. Anal. At. Spectrom. 2 (1987) 269-276.

[8] K.E. Jarvis, Determination of REE in geological samples by inductively coupled plasma mass spectrometry, J. Anal. At. Spectrom. 4 (1989) 563-570.

[9] L. Haichen, L. Ying, Z. Zhanxia, Determination of ultratrace rare earth elements in chondritic meteorites by inductively coupled plasma mass spectrometry, Spectrochim. Acta Part B 53 (1997) 1399-1404.

[10] X.P. Yan, R. Kerrich, M.J. Hendry, Flow injection online group pre-concentration and separation of (Ultra) trace rare-earth elements in environmental and geological samples by precipitation using knotted reactor as filterless collector for inductively coupled plasma mass spectrometric determination, J. Anal. At. Spectrom. 14 (1999) 215-221.

[11] V. Balaram, Inductively coupled plasma mass spectrometric techniques in the elemental and isotopic analysis of lanthanides and actinides, J. Indian Chem. Soc. 79 (2002) 479-485.

[12] A. Montaser, D.W. Golightly, Inductively Coupled Plasma in Analytical Atomic Spectrometry, 2nd ed, VCH, New York, 1992.

[13] M.E. Ketterer, J.J. Reschl, M.J. Peters, Multivriate calibration in inductively coupled plasma mass spectrometry, Anal. Chem. 61 (1989) 2031-2040.

[14] K. Kawaguchi, Y Kishi, O. Kawaguchi, Y. Watanabe, Y. Inoue, Determination of rare earth elements by inductively coupled plasma mass spectrometry with ion chromatography, Anal. Chem. 63 (1991) 2137-2140.

[15] K.E. Jarvis, A.L. Gray, E. McCurdy, Avoidance of spectral interference on eurpium in inductively coupled plasma mass spectrometry by sensitive measurement of doubly charged ion, J. Anal. At. Spectrom. 4 (1989) 743-747.

[16] L. Halicz, I. Segal, O. Yoffe, Direct REE determination in fresh waters using ultrasonic nebulization ICP-MS, J. Anal. At. Spectrom. 14 (1999) 1579-1581.

[17] H. Tao, A. Miyazaki, Decrease of solvent water loading in inductively coupled plasma mass spectrometry by using a membrane separator, J. Anal. At. Spectrom. 10 (1995) 1-5.

[18] C. Pin, P. Telouk, J.L. Imbert, Direct determination of Sm: Nd ratio in geological material by inductively coupled plasma quadrupole mass spectrometry with cryogenic desolvation. Comparison with isotope dilution thermal ionization mass spectrometry, J. Anal. At. Spectrom. 10 (1995) 93-98.

[19] J.W.H. Lam, G. Horlick, A comparison of Ar and mixed gas plasmas for inductively coupled plasma mass spectrometry, Spectrochim. Acta Part B 45 (1990) 1313-1325.

[20] J.M. Craig, D. Beauchemin, Reduction of the effects of concomitant elements in inductively coupled plasma mass spectrometry by adding nitrogen to the plasma gas, J. Anal. At. Spectrom. 7 (1992) 937-942.

[21] H. Louie, S.Y.P. Soo, Use of nitrogen and hydrogen in inductively coupled plasma mass spectrometry, J. Anal. At. Spectrom. 7 (1992) 557-564.

[22] M.A. Vaughan, G. Horlick, Effect of sampler and skimmer orfice size on analyte and analyte oxide signals in inductively coupled plasma mass spectrometry, Spectrochim. Acta Part B 45 (1990) 1289-1299.

[23] J.W.H. Lam, G. Horlick, Effect of sampler-skimmer separation in inductively coupled plasma mass spectrometry, Spectrochim. Acta Part B 45 (1990) 1327-1338.

[24] E.H. Van Veen, S. Bosch, M.T.C. De Loos-Vollebregt, Spectral interpretation and interference correction in 
inductively coupled plasma atomic emission spectrometry, Spectrochim. Acta Part B 49 (1994) 1347-1361.

[25] P. Dulski, Interference of oxide, hydroxide and chloride analyte species in the determination of rare earth elements in geological samples by inductively coupled plasma mass spectrometry, Fresenius Z. Anal. Chem. 350 (1994) 194-203.

[26] M.A. Vaughan, G. Horlick, Correction procedures for rare earth element analysis in inductively coupled plasma mass spectrometry, Appl. Spectrosc. 44 (1990) 587-593.

[27] X. Cao, M. Yin, X. Wang, Elimination of the spectral interference from polyatomic ions with rare earth elements in inductively coupled plasma mass spectrometry by combining algebraic correction with chromatographic separation, Spectrochim. Acta Part B 56 (2001) 431-441.

[28] Y. Hu, F. Vanhaecke, L. Moens, R. Dams, P. del Castilho, J. Japenga, Determination of aqua-regia soluble content of rare earth element in fertilizer, animal fodder, phosphate and manure samples using inductively coupled plasma mass spectrometry, Anal. Chim. Acta 373 (1998) 95-105.

[29] S.H. Ke, L.S. Huang, J.S. Huang, K.C. Lin, Flow injection inductively coupled plasma mass spectrometer incorporated with an ultrasonic nebulizer membrane dryer: application to trace lead detection in aqueous solution and sea water, Appl. Spectrosc. 55 (2001) 604-610.

[30] K. Ashley, R.N. Andrews, L. Cavazos, M. Demange, Ultrasonic extraction as a sample preparation technique for elemental analysis by atomic spectrometry, J. Anal. At. Spectrom. 16 (2001) 1147-1153.

[31] N.M. Raut, L.S. Huang, S.K. Aggarwal, K.C. Lin, Mathematical correction for polyatomic isobaric spectral interferences in the determination of lanthanides by inductively coupled plasma mass spectrometry, to be submitted for publication.

[32] D.J. Douglas, J.B. French, An improved interface for inductively coupled plasma mass spectrometry, Spectrochim. Acta Part B 41 (1986) 197-204.

[33] F.E. Lichte, A.L. Meier, J.G. Crock, Determination of rare earth element in geological material by inductively coupled plasma mass spectrometry, Anal. Chem. 59 (1987) 1150-1157.

[34] G. Horlick, S.H. Tan, M.A. Vaughan, C.A. Rose, The effect of plasma operating parameters on analyte signals in inductively coupled plasma mass spectrometry, Spectrochim. Acta Part B 40 (1985) 1555-1572.

[35] M.A. Vaughan, G. Horlick, S.H. Tan, Effect of operating parameters on analyte signals in inductively coupled plasma mass spectrometry, J. Anal. At. Spectrom. 2 (1987) 765-772.

[36] J.K. Aggarwal, M.B. Shabani, M.R. Palmer, K. Vala Ragnarsdottir, Determination of the rare earth elements in aqueous samples at sub ppt levels by inductively coupled plasma mass spectrometry and flow injection inductively coupled plasma mass spectrometry, Anal. Chem. 68 (1996) 4418-4423.

[37] A.J. Walder, I.T. Platzner, P.A. Freedman, Isotope ratio measurement of lead, neodymium and neodymiumsamarium mixtures, hafnium and hafnium-lutetium mixtures with a double focussing multiple collector inductively coupled plasma mass spectrometer, J. Anal. At. Spectrom. 8 (1993) 19-23.

[38] I.T. Platzner, Isotope ratio mass spectrometry-state of the art, Proceedings of the Eighth ISMAS Symposium on Mass Spectrometry, Hyderabad, India, December, 1999, pp. 307-319. 